\title{
Glutathione Reductase, Liver Transaminases and Atypical Lymphocytes Count as Early Predictive Biomarkers in Diagnosis of Thrombocytopenia in Dengue Viral Infection
}

\author{
Samantha Bandara ${ }^{1 *}$, Lal G. Chandrasena ${ }^{2}$, Hemantha Peiris ${ }^{3}$, Visula Abesuriya ${ }^{2}$, \\ Arjuna De Silva4, Chandima De Mel2 ${ }^{2}$, Sanjay De Mel5, Suranjith L. Seneviratne ${ }^{6}$ \\ ${ }^{1}$ Department of Medical Laboratory Sciences, Faculty of Allied Health Sciences, University of Sri Jayewardenepura, Nugegoda, Sri Lanka \\ ${ }^{2}$ Nawaloka Hospitals Research and Education Foundation, Nawaloka Hospitals PLC, Colombo, Sri Lanka \\ ${ }^{3}$ Department of Biochemistry, Faculty of Medical Sciences, University of Sri Jayewardenepura, Nugegoda, Sri Lanka \\ ${ }^{4}$ Department of Medicine, Faculty of Medicine, University of Kelaniya, Ragama, Sri Lanka \\ ${ }^{5}$ Department of Haematology-Oncology, National University Cancer Institute, National University Health System, Singapore \\ ${ }^{6}$ Institute of Immunity and Transplantation, Royal Free Hospital and University College, London, UK \\ Email: *ems.bandara@sjp.ac.lk
}

How to cite this paper: Bandara, S., Chandrasena, L.G., Peiris, H., Abesuriya, V., De Silva, A., De Mel, C., De Mel, S. and Seneviratne, S.L. (2021) Glutathione Reductase, Liver Transaminases and Atypical Lymphocytes Count as Early Predictive Biomarkers in Diagnosis of Thrombocytopenia in Dengue Viral Infection. Journal of Biosciences and Medicines, 9, 119-130. https://doi.org/10.4236/jbm.2021.91010

Received: December 3, 2020

Accepted: January 25, 2021

Published: January 28, 2021

Copyright ( 2021 by author(s) and Scientific Research Publishing Inc. This work is licensed under the Creative Commons Attribution International License (CC BY 4.0).

http://creativecommons.org/licenses/by/4.0/ (c) (i) Open Access

\begin{abstract}
Objective: The aim of the study is to identify whether Atypical Lymphocyte (AL), liver transaminases, and Glutathione Reductase (GR) can be used as potential biomarkers in the assessment of severity and thrombocytopenia in dengue. Methods: A cross-sectional analytical study was carried out on diagnosed dengue patients admitted to Nawaloka Hospital, Sri Lanka. Blood samples were taken from patients $(n=50)$ on the day of admission, $3^{\text {rd }}$ and $5^{\text {th }}$ day from admission for analysis of GR, aspartate transaminase, alanine transaminase, platelets, white blood cells, and Atypical Lymphocytes (AL). Results: GR level of all three measured stages had a higher area under the curve $(>88 \%)$, high sensitivity and specificity compared to liver transaminases. A significant regression model represents on admission GR and AL levels as predictive variables to platelet levels in day 03 from admission (Day 3 Platelet level $=127155.3-383{ }^{*} \mathrm{GR}-0.431 * \mathrm{AL}$ ). Conclusion: Liver transaminases, GR, and AL\% can be considered as a profile of predictive biomarkers in early diagnosis of severity of dengue infection. The degree of thrombocytopenia can be predicted using on admission GR and AL\% level in acute dengue viral infection.
\end{abstract}

\section{Keywords}

Dengue, Liver Transaminases, Glutathione Reductase, Atypical Lymphocytes 


\section{Introduction}

Dengue is a mosquito-borne viral disease, extent in many tropical and subtropical regions in the world. A recent estimate indicates more than 390 million dengue infections with 96 million manifests clinically [1]. Dengue virus belongs to family Flaviviridae consisting of four different antigenic serotypes [2]. Dengue virus causes Dengue Fever (DF) with the most severe and life-threatening forms being Dengue Hemorrhagic Fever (DHF) and Dengue Shock Syndrome (DSS) [3].

Dengue Fever is diagnosed by several laboratory methods and clinical symptoms. The most used laboratory methods are virus isolation, detection of viral RNA, detection of Nonstructural Protein1 (NS1) antigens and antibody detection (IgG and IgM) [4]. World Health Organization criteria classify dengue according to levels of severity as dengue without warning signs, dengue with warning signs (abdominal pain, persistent vomiting, fluid accumulation, mucosal bleeding, lethargy, liver enlargement, increasing hematocrit with decreasing platelets), and severe dengue (dengue with severe plasma leakage, severe bleeding, or organ failure) [5]. All of above-mentioned laboratory methods and clinical classifications are only to diagnose dengue fever and not predicting the severity of the disease.

Studies have reported several biomarkers such as serum lactate dehydrogenase, creatine kinase, and albumin levels at 48 - 96 hours after onset of fever to predict severity acute dengue fever [6]. Timely assessment of liver transaminases was also identified as a predictive indicator of the severity of dengue fever [7]. A consistent high serum chymase level also reported as a predictive marker of dengue hemorrhagic fever [8].

Experimental fact of immune pathology is a fundamental requirement in elucidating of severe dengue fever [9]. Both innate and acquired immune responses are also identified as predictive markers in dengue fever. The primary response against dengue infection is the internalization of the pathogen by an overwhelming number of immune cells and the production of antibodies. Atypical lymphocytes (CD19+ B lymphocytes) are antibody immune reactions to the dengue virus, which significantly increase in anti-dengue IgG antibodies during the secondary dengue infection. Increased proportion of atypical plasmacytoid lymphocytes have also been described in patients with dengue infection [10]. Atypical Lymphocytes (AL) and CD19+ cell counts have been identified as useful diagnostic tools for identification of the severity of dengue infection and the recovery from the disease [11] [12]. On admission AL count has proposed as a negative predictive factor for severe thrombocytopenia in day 5 day 7 of dengue fever [13].

Dengue virus generates oxidative stress through the effect of NADPH oxidase. This triggers the inflammatory cytokine response, contributing to the pathogenesis of dengue viral infection [14]. Thus the antioxidants play a crucial role in host defense against dengue viral infection [15]. Increased level levels of Superoxide Dismutase (SOD), Malondialdehyde (MDA), and Nitric Oxide (NO), and decreased levels of Trolox equivalent antioxidant capacity in plasma, serum pa- 
raoxonase, erythrocyte glutathione, and Glutathione Peroxidase (GPx) activities have been reported as useful biomarkers of dengue infection [16] [17].

Hepatic dysfunction is a well-recognized feature of dengue infections, often demonstrated by hepatomegaly and mild to moderate increases in transaminase levels [18]. The dengue associated liver injury can be both viral induced or immune mediated. This has been shown in dengue virus infected hepatocytes in mouse models [19].

Glutathione Reductase (GR) is one of the antioxidant enzymes, which is directly responsible in maintaining of reduced glutathione level by recycling of oxidized glutathione [20]. Serum Aspartate Aminotransferase (AST) and Alanine Aminotransferase (ALT) are most commonly used markers to monitor acute liver injury. Therefore, present study assessed the longitudinal changes (on admission, $3^{\text {rd }}$ day from admission and $5^{\text {th }}$ day from admission) of AL, GR, AST and ALT as predictive indicators of severity and thrombocytopenia in dengue viral infection. Currently, there is no valid laboratory test available to predict the severity of dengue infection. Therefore, the present study has been identified whether these biomarkers can be used as potential biomarkers in the assessment of severity and thrombocytopenia in dengue viral infection.

\section{Materials and Methods}

A cross sectional analytical study was carried out on dengue patients admitted to Nawaloka Hospital (NH), Sri Lanka, from January to August 2019.

\subsection{Ethical Approval}

Ethical approval for the study was obtained from the Ethics Review Committee (Reference Number: NHREF/9/18), Nawaloka Hospitals, Colombo 02, Sri Lanka. Informed written consent was obtained from each the patient or by parent/guardian prior to sampling.

\subsection{Study Sample}

A hospital-based study was carried out with 50 patients (Male-29, Female-21), age 12 years and above positive for dengue antigen NS1 (SD BIOLINE Dengue NS1 kit, Standard Diagnostics, Gyeonggi, South Korea) and admitted at medical units at Nawaloka Hospital, Colombo, Sri Lanka.

\subsection{Data Collection}

Venous blood samples $(5 \mathrm{ml})$ were collected from patients on admission, $3^{\text {rd }}$ day from admission and $5^{\text {th }}$ day from admission for analysis of laboratory parameters such as AST, ALT, GR levels, platelet, and white blood cells count. The clinical parameters such as presenting symptoms, vital signs and dengue warning signs were recorded throughout the study period.

\subsection{Sample Analysis}

Blood samples were collected into lithium heparin tubes and separated serum 
was immediately stored in aliquot at $-20^{\circ} \mathrm{C}$. GR antioxidants concentrations were determined by Randox commercial assay kit (Ransel test kit, Randox Laboratories, UK) on Dimension clinical chemistry analyzer (Germany). The serum sample was used to detect AST and ALT (Cobas, Germany) by the Cobas clinical chemistry analyzer (Roche, Germany). The blood samples collected into EDTA tubes were used to assess the full blood count using the Sysmex haematology analyzer (XS500i, Japan).

The dengue severity levels of patients were categorized according to 2009 WHO criteria [5].

\subsection{Statistics}

The statistical analysis was performed using SPSS version 25.0. Descriptive statistics were given as measures of central tendency and frequencies. The Shapiro-Wilk test was performed to test the normal distribution. Paired sample t-test or Wilcoxon signed rank test was used to determine any statistically significant differences of biochemical parameters between admission days. Pearson correlation coefficients ( $r$ ) were used to analyze the associations between AL\% with GSH, AST and ALT. Receiver Operating Characteristic (ROC) analysis was used to obtain sensitivity, specificity and cut of values of GR, AST and ALT levels to predict severity of dengue fever in relation to AL\%. A linear regression model was developed to predict platelet level in $03^{\text {rd }}$ day from admission by using on admission GR and AL\%. Statistical significance was defined as $\mathrm{p}<005$.

\section{Results}

The study recruited 50 patients (male-29 and female-21, average age $31.6 \pm$ 13.5 years), who were confirmed as having Dengue fever by rapid immunochromatography test (NS1). All of the patients were admitted on day 03 of fever. The clinical symptoms of patients recorded on admission are depicted in Table 1. A significantly high percentage of patients were recorded body pain (100\%) and headache $(83.3 \%)$ on admission.

Table 2 shows GR, ALT, AST, AL, platelet count and total white blood cell (WBC) count of dengue patients. There were statistically significant differences of all parameters on admission, day 3 , and day 5 from admission. Although these parameters were significant, GR, AST, ALT levels were observed very high on $3^{\text {rd }}$ day from admission compared to day 0 and day 5. The highest AL\% was observed on admission.

However, results showed that the test values of day 3 from admission were significantly higher than the rest of the days indicating that day 3 from admission is appeared to be very important as far as clinical management of patients is concerned.

Furthermore, the Pearson correlation showed a significant positive coefficient of AL\% with GR, AST, and ALT in the respective days of admission (Figure 1). 
Table 1. Clinical signs and symptoms of DF patients.

\begin{tabular}{|c|c|c|}
\hline & Yes & No \\
\hline \multicolumn{3}{|c|}{ Clinical symptoms } \\
\hline Nausea & $41 \%$ & $59 \%$ \\
\hline Headache & $83.3 \%$ & $16.7 \%$ \\
\hline Retro orbital pain & $25 \%$ & $75 \%$ \\
\hline Abdominal pain & $11.4 \%$ & $88.6 \%$ \\
\hline Arthralgia Myalgia & $100 \%$ & $0 \%$ \\
\hline Restless & $11.9 \%$ & $88.1 \%$ \\
\hline \multicolumn{3}{|c|}{ Clinical signs } \\
\hline Macular skin rash & $8.9 \%$ & $91.1 \%$ \\
\hline Petechial rash & $11.9 \%$ & $88.1 \%$ \\
\hline Vomiting & $11.1 \%$ & $88.9 \%$ \\
\hline Haematemesis & $11.1 \%$ & $88.9 \%$ \\
\hline Melena & $11.6 \%$ & $88.4 \%$ \\
\hline Diarrhea & $35.6 \%$ & $64.4 \%$ \\
\hline Bleeding Manifestation & $11.6 \%$ & $88.4 \%$ \\
\hline RHS tenderness & $47.6 \%$ & $52.1 \%$ \\
\hline Epigastric Tenderness & $20.8 \%$ & $79.2 \%$ \\
\hline Hepatomegaly & $10.4 \%$ & $89.6 \%$ \\
\hline Respi. Distress & $10.4 \%$ & $89.6 \%$ \\
\hline Petechiae & $10.4 \%$ & $89.6 \%$ \\
\hline Impaired conscious & $10.9 \%$ & $89.1 \%$ \\
\hline
\end{tabular}

Table 2. Summary table of biochemical and haematological parameters of patients.

\begin{tabular}{cccc}
\hline & $\begin{array}{c}\text { On admission } \\
(\text { Mean } \pm \text { SD })\end{array}$ & $\begin{array}{c}3^{\text {rd }} \text { day from the } \\
\text { admission } \\
(\text { Mean } \pm \text { SD })\end{array}$ & $\begin{array}{c}05^{\text {th }} \text { day from the } \\
\text { admission } \\
(\text { Mean } \pm \text { SD })\end{array}$ \\
\hline ALT (IU/L) & $68.5 \pm 47.6$ & $125.9 \pm 133.0^{*}$ & $91.8 \pm 89.8$ \\
AST (IU/L) & $71.2 \pm 58.2$ & $144.2 \pm 144.8^{*}$ & $93.8 \pm 71.7$ \\
GR (U/L) & $100.9 \pm 25.5$ & $130.2 \pm 35.1^{*}$ & $119.8 \pm 29.2$ \\
PLT (per $\mu \mathrm{l})$ & $97,600 \pm 33,000$ & $65,100 \pm 26,500^{*}$ & $85,300 \pm 21,300$ \\
WBC (per $\mu \mathrm{l})$ & $2460 \pm 880$ & $3500 \pm 1220$ & $4770 \pm 1770$ \\
AL (\%) & $0.64 \pm 0.35^{\dagger}$ & $0.43 \pm 0.24$ & $0.30 \pm 0.18$ \\
\hline
\end{tabular}

${ }^{*}$ The values were significantly different $(\mathrm{p}<0.05)$ compared to on admission and day 05 from admission, ${ }^{+}$The values of on admission appeared to be significantly high $(\mathrm{p}<0.05)$ compared to day 03 and day 05 from admission.

These biochemical markers were also compared with the atypical lymphocyte count on three testing days and the GR, AST and ALT levels were significantly higher (Table 3) among dengue patients with on admission atypical lymphocyte count was more than $0.55 \%$ [12].

ROC curves analyze (Table 4) using on admission atypical lymphocyte 


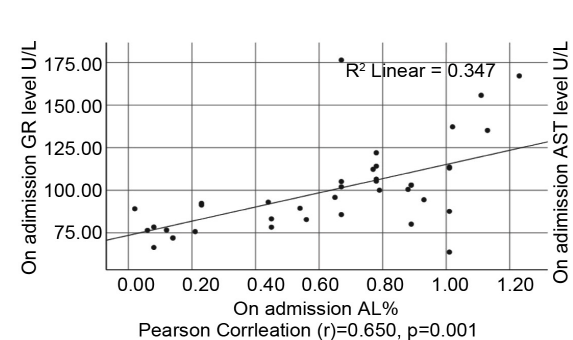

Pearson Corrleation $(r)=0.650, p=0.001$

(a)

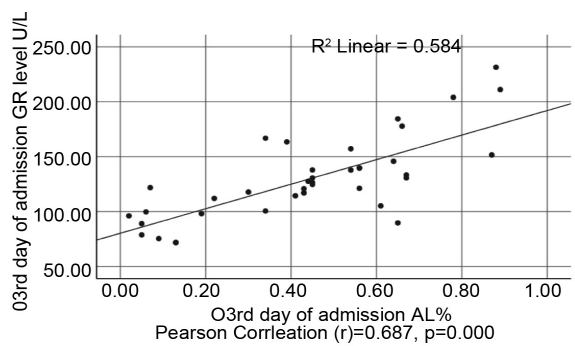

(d)

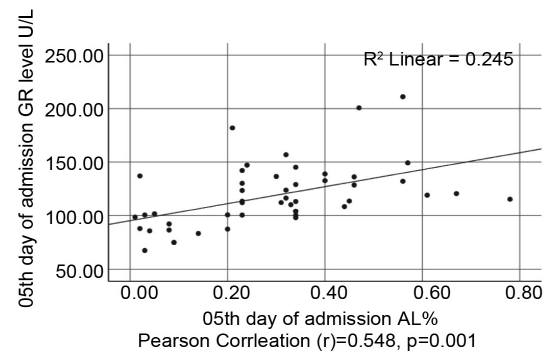

(g)

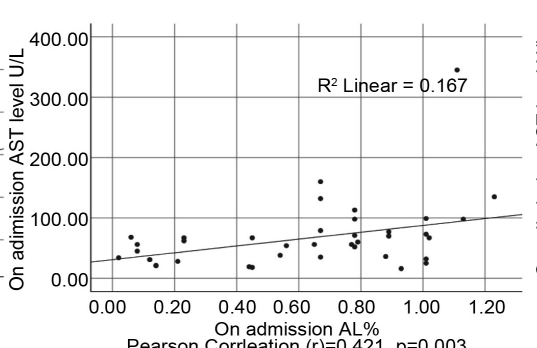

(b)

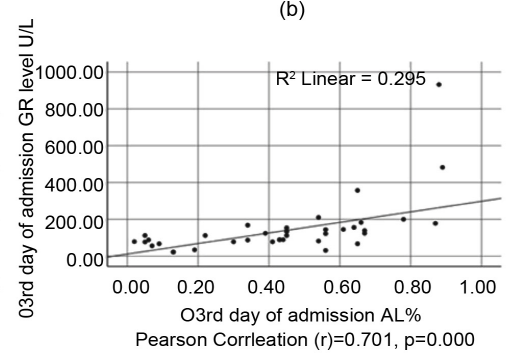

(e)

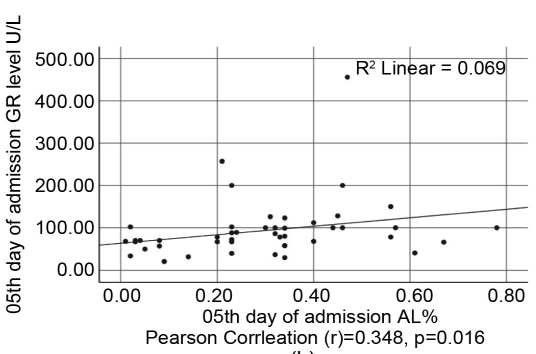

(h)

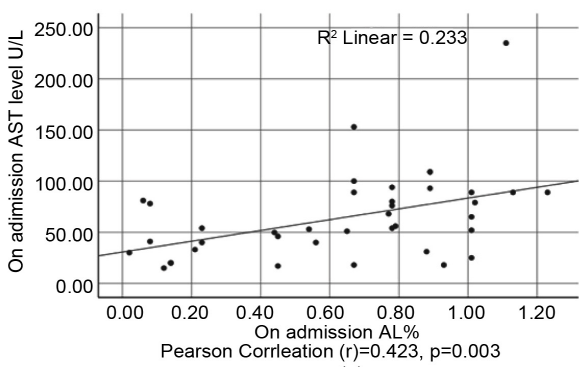

(c)
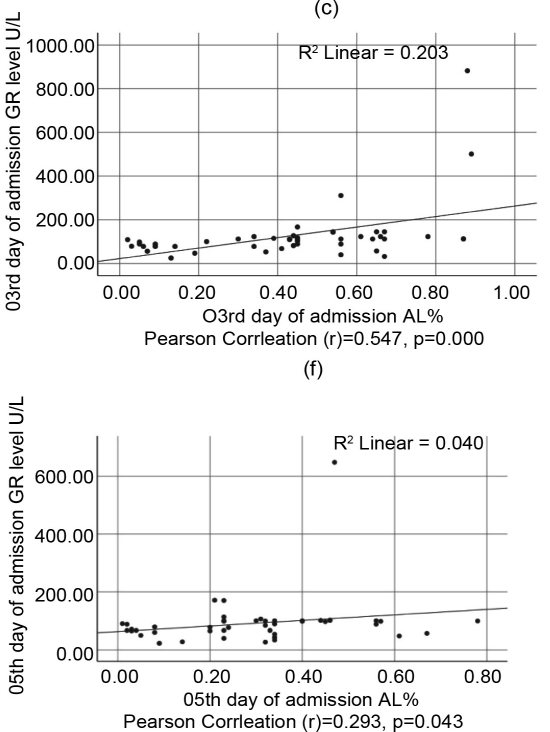

(I)

Figure 1. Correlation between AL\% with GR, AST and ALT on admission, day 3 from admission and day 5 from admission, (a): On admission AL\% and GR level; (b): On admission AL\% and AST level; (c): On admission AL\% and ALT level; (d): Day 3 from admission AL\% and GR level; (e): Day 3 from admission AL\% and AST level; (f): Day 3 from admission AL\% and ALT level; (g): Day 5 from admission AL\% and GR level; (h): Day 5 from admission AL\% and AST level; (i): Day 5 from admission AL\% and ALT level.

count $>0.55 \%$ as an indicator of the severity of dengue infection, shown that the GR level of all three measured stages had a higher area under the curve (>88\%), high sensitivity and specificity compared to liver transaminases.

Furthermore to the above ROC curves data were reanalyzed to find out whether there is any relationship between the platelet count of day 03 and day 0 values of other parameters by using ROC curves of 03 models (Figure 2). All of the models of ROC curves had significant areas under the curves $>0.8$ with the same cut off value for day 03 platelet levels $(69,000 /$ per $\mu \mathrm{l})$. This indicates the patients on the day admission showed GR, AST, ALT, and AL\% levels more than above observed cut-offs (Table 4), have been decreased their platelet level less than $69,000 \mathrm{per} / \mu \mathrm{l}$ on day 03 from admission. However, total white blood cell count was not observed significant changes with the above biomarkers.

In addition, we developed a regression model to predict platelet level on day 03 from admission by using on admission variables GR, AST, ALT, and AL (Table 5). A significant regression model represents on admission GR and AL levels as predictive variables to platelet levels in day 03 from admission (Day 03 Platelet level $=127155.3-383 * \mathrm{GR}-0.431 * \mathrm{AL}$ ). 


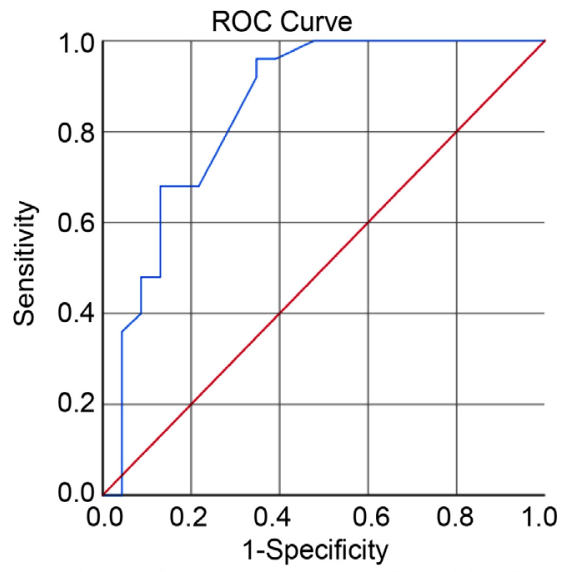

Diagonal segments are produced by ties

(a)

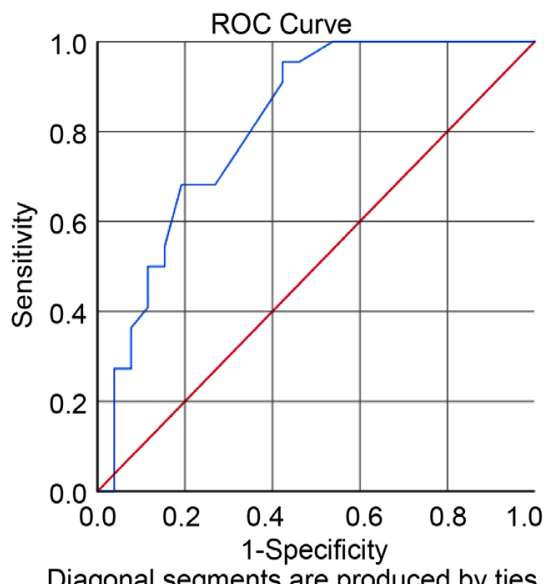

Diagonal segments are produced by ties

(b)

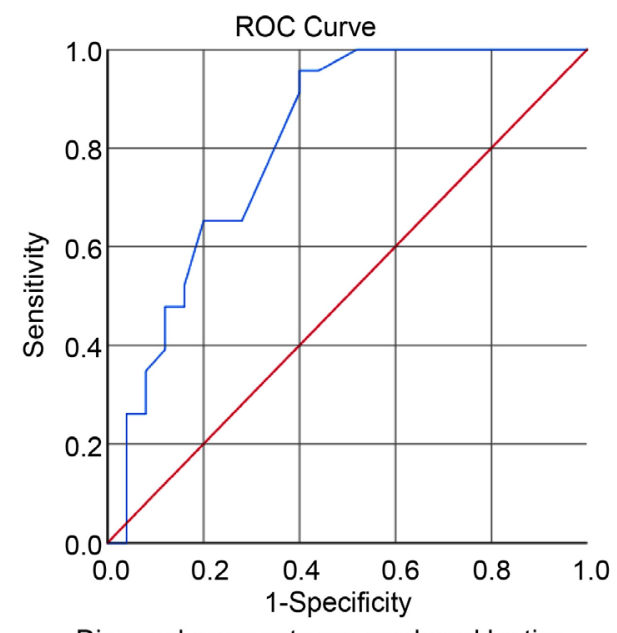

Diagonal segments are produced by ties

(c)

Figure 2. ROC curves for $3^{\text {rd }}$ day of admission platelet count respective to (a): On admission cut-off of GR and AL\%; (b): On admission cut-off of GR, AST and AL\%; and (c): On admission cut-off of GR, AST, ALT and AL\%.

Table 3. Comparison of AL count $>0.55 \%$ and GR, AST and ALT levels on admission, day 3 and day 5 from admission.

\begin{tabular}{|c|c|c|c|c|c|c|}
\hline & \multicolumn{2}{|c|}{ GR (IU/L) } & \multicolumn{2}{|c|}{ AST (IU/L) } & \multicolumn{2}{|c|}{ ALT (IU/L) } \\
\hline & $\begin{array}{c}\mathrm{AL}>0.55 \% \\
\mathrm{n}=31\end{array}$ & $\begin{array}{c}\mathrm{AL}<0.55 \% \\
\mathrm{n}=19\end{array}$ & $\begin{array}{c}\mathrm{AL}>0.55 \% \\
\mathrm{n}=31\end{array}$ & $\begin{array}{c}\mathrm{AL}<0.55 \% \\
\mathrm{n}=19\end{array}$ & $\begin{array}{c}\mathrm{AL}>0.55 \% \\
\mathrm{n}=31\end{array}$ & $\begin{array}{c}\mathrm{AL}<0.55 \% \\
\mathrm{n}=19\end{array}$ \\
\hline On admission & $110.7 \pm 26.3^{\star}$ & $83.2 \pm 9.5$ & $\begin{array}{c}86.5 \pm \\
66.4^{\star}\end{array}$ & $43.4 \pm 20.3$ & $82.1 \pm 52.8^{\star}$ & $43.6 \pm 20.2$ \\
\hline $\begin{array}{c}\text { Day } 03 \text { from } \\
\text { admission }\end{array}$ & $145.2 \pm 31.1^{\star}$ & $102.8 \pm 23.8$ & $\begin{array}{c}182.4 \pm \\
167.1^{\star}\end{array}$ & $74.5 \pm 36.1$ & $\begin{array}{c}152.0 \pm \\
159.4^{*}\end{array}$ & $78.3 \pm 27.8$ \\
\hline $\begin{array}{l}\text { Day } 05 \text { from } \\
\text { admission }\end{array}$ & $130.6 \pm 26.3^{\star}$ & $96 \pm 21.9$ & $110.4 \pm 81.0^{*}$ & $60.7 \pm 23.4$ & $\begin{array}{c}105.0 \pm \\
106.0^{*}\end{array}$ & $65.1 \pm 23.9$ \\
\hline
\end{tabular}

${ }^{*} \mathrm{GR}, \mathrm{AST}$ and ALT levels of on admission, day 3 and day 5 from admission were significantly high when on admission $\mathrm{AL}>0.55 \%$. 
Table 4. The sensitivity, specificity and cut of values of GR, AST and ALT levels to predict severity of dengue fever in relation to atypical lymphocyte level.

\begin{tabular}{|c|c|c|c|c|}
\hline $\begin{array}{l}\text { Biochemical } \\
\text { parameters }\end{array}$ & Area under the curve (AUC) & $\begin{array}{l}\text { Sensitivity } \\
(\%)\end{array}$ & $\begin{array}{l}\text { Specificity } \\
(\%)\end{array}$ & $\begin{array}{l}\text { Cut off } \\
\text { values } \\
\text { (IU/L) }\end{array}$ \\
\hline \multicolumn{5}{|c|}{ GR } \\
\hline On admission & $\begin{array}{c}0.884 \\
(95 \%, \mathrm{CI}=79 \%-97.8 \%)\end{array}$ & 80.6 & 82.4 & 92.5 \\
\hline $\begin{array}{l}3^{\text {rd }} \text { day from } \\
\text { admission }\end{array}$ & $0.894(95 \%, C I=79 \%-99.9 \%)$ & 83.9 & 77.4 & 121.0 \\
\hline $\begin{array}{l}5^{\text {th }} \text { day from } \\
\text { admission }\end{array}$ & $0.896(95 \%, \mathrm{CI}=76 \%-99.9 \%)$ & 96.8 & 64.7 & 100.3 \\
\hline \multicolumn{5}{|c|}{ AST } \\
\hline On admission & $0.764(95 \%, \mathrm{CI}=63 \%-89.7 \%)$ & 80.6 & 58.8 & 47.5 \\
\hline $\begin{array}{l}3^{\text {rd }} \text { day from } \\
\text { admission }\end{array}$ & $0.866(95 \%, \mathrm{CI}=75.7 \%-97.5 \%)$ & 87.1 & 70.6 & 84.5 \\
\hline $\begin{array}{l}5^{\text {th }} \text { day from } \\
\text { admission }\end{array}$ & $0.777(95 \%, C I=64.4 \%-91 \%)$ & 77.4 & 41.2 & 66.5 \\
\hline \multicolumn{5}{|c|}{ ALT } \\
\hline On admission & $0.775(95 \%, \mathrm{CI}=64.6 \%-90.4 \%)$ & 77.4 & 58.8 & 47.9 \\
\hline $\begin{array}{l}3^{\text {rd }} \text { day from } \\
\text { admission }\end{array}$ & $0.815(95 \%, \mathrm{CI}=69.2 \%-93.8 \%)$ & 77.4 & 70.6 & 93.5 \\
\hline $\begin{array}{l}5^{\text {th }} \text { day from } \\
\text { admission }\end{array}$ & $0.728(95 \%, \mathrm{CI}=58.5 \%-87 \%)$ & 67.7 & 64.7 & 77.5 \\
\hline
\end{tabular}

Table 5. Regression model to predict platelet level depending on admission variables.

\begin{tabular}{|c|c|c|c|c|c|c|c|c|}
\hline \multicolumn{9}{|c|}{ Coefficients } \\
\hline & \multirow{2}{*}{ Model } & \multicolumn{2}{|c|}{$\begin{array}{l}\text { Unstandardized } \\
\text { Coefficients }\end{array}$} & \multirow{2}{*}{$\begin{array}{c}\text { Standardized } \\
\text { Coefficients } \\
\text { Beta }\end{array}$} & \multirow{2}{*}{$\mathrm{t}$} & \multirow{2}{*}{ Sig. } & \multicolumn{2}{|c|}{$\begin{array}{c}95.0 \% \text { Confidence Interval } \\
\text { for B }\end{array}$} \\
\hline & & B & Std. Error & & & & Lower Bound & $\begin{array}{l}\text { Upper } \\
\text { Bound }\end{array}$ \\
\hline \multirow{5}{*}{1} & (Constant) & $127,155.279$ & $11,989.162$ & & 10.606 & 0.000 & $102,976.829$ & $151,333.729$ \\
\hline & $\mathrm{GR}^{*}$ & -397.065 & 156.295 & -0.383 & -2.540 & 0.015 & -712.264 & -81.867 \\
\hline & $\mathrm{AST}^{*}$ & -31.010 & 61.032 & -0.068 & -0.508 & 0.614 & -154.093 & 92.072 \\
\hline & $\mathrm{ALT}^{*}$ & 5.842 & 26.431 & 0.029 & 0.221 & 0.826 & -47.462 & 59.145 \\
\hline & $\mathrm{AL}^{*}$ & $-32,315.973$ & 9586.794 & -0.431 & -3.371 & 0.002 & $-51,649.587$ & $-12,982.359$ \\
\hline
\end{tabular}

Dependent Variable: Platelet level - day 3 from admission. ${ }^{*}$ on admission variables. Regression model; Day 3 Platelet level $=127,155.3-383 * \mathrm{GR}-0.431 * \mathrm{AL}$ ).

\section{Discussion}

This study was carried out to determine the predictive power of GR, liver transaminases, and AL\% on prediction severity and thrombocytopenia level in dengue viral infection. A previous study has observed a higher level of AL count among dengue/dengue hemorrhagic fever patients compared to patients with 
dengue like syndrome [11]. The percentage of AL count was higher among patients with respiratory compromise, hypotension, and bleeding symptoms. These results suggested that a higher level of AL\% is associated with increased complications of dengue infection, leading to severe dengue and $>0.55 \%$ of AL count as a predictive marker for severity of dengue infection with higher sensitivity and specificity [12].

The present study showed that serum liver transaminases (AST and ALT) and GR levels correlated positively with AL\%. All of these markers had high sensitivity and specificity to diagnose the severity of dengue infection along with AL\%. Among these parameters percentage of AL and GR had a significant effect to predict platelet count of $3^{\text {rd }}$ day from admission.

Even though there was no consistency in reported data on GPx and glutathione among dengue patients. Glutathione or glutathione derivatives are tested as a therapeutic agent to decrease oxidative stress in various diseases including dengue [21] [22] [23]. This probably would have contributed to maintain the reduced glutathione by reduction of oxidized glutathione. GR is responsible for supplying of reduced glutathione to control of cellular reactive oxygen species. Therefore, the recycling of oxidized glutathione is more essential to have effectively reduced glutathione for continued cell function [20]. Thus, the GR enzyme level has a potential being used as a predictive marker for early identification of dengue viral fever ( $3^{\text {rd }}$ day from admission). The activity of GR may be reduced in day 5 from admission with decreasing of reactive oxygen species and severity of the disease. Furthermore, the multiple regression analysis proved that the GR level on admission and AL\% appear to be as prominent predictive markers in association with a platelet count of day 3 of the infection.

Liver involvement of dengue fever and biochemical changes have discussed in various studies as very mild to severe liver disease [18] [24] [25]. Moderate elevation of liver enzymes of AST and ALT have also been reported (93 - 174 IU/L and 86 to $88.5 \mathrm{U} / \mathrm{L}$ ) in different studies [26] [27]. In the present study, 95\% of dengue patients also had similar ranges of transaminases. The majority of the patients showed the high values of transaminases on day 03 from admission (5 6 days of onset of fever) in the present study. The studies also reported an increased level of liver enzymes correlated with the severity of the diseases [28] [29]. Similarly, we also reported observed on admission AST and ALT levels showed high sensitivity and specificity with the severity of dengue infection versus AL\%.

These findings suggest that liver transaminases, GR and AL\% play an important role in the determination of the severity of dengue infection. Furthermore, GR and AL\% also can be used as predictive biomarkers in the determination of thrombocytopenia in dengue patients.

In summary, our study proposed combination of liver transaminases, GR, AL\% with the degree of thrombocytopaenia with high sensitivity and specificity biomarkers as a profile test in early diagnosis of severity of dengue infection. This is the first study reported on the early diagnosis and prediction of throm- 
bocytopenia in acute dengue viral infection. Further investigations are needed to elucidate the changes and association of total antioxidant capacity to predict severity of dengue fever over the period of admission to discharge.

\section{Acknowledgements}

This work was supported by Nawaloka Hospitals Research and Education Foundation, Nawaloka Hospitals PLC, Colombo, Sri Lanka (Grant number: NHREF/RG/17/04). Further, we would like to extend our gratitude to Dr. Inoka Uluwaduge, Department of Basic Sciences, University of Sri Jayewardenepura for her contribution in proof reading, the patients who consented to be part of this study, and the staff at Nawaloka Haematology and Chemical Pathology Laboratories for their assistance.

\section{Conflicts of Interest}

The authors declare that they have no competing interests.

\section{References}

[1] Bhatt, S., Gething, P.W., Brady, O.J., Messina, J.P., Farlow, A.W., Moyes, C.L., et al. (2013) The Global Distribution and Burden of Dengue. Nature, 496, 504-507. https://doi.org/10.1038/nature12060

[2] Mangold, K.A. and Reynolds, S.L. (2013) A Review of Dengue Fever: A Resurging Tropical Disease. Pediatric Emergency Care, 29, 665-669. https://doi.org/10.1097/PEC.0b013e31828ed30e

[3] Huy, N.T., Van Giang, T., Thuy, D.H., Kikuchi, M., Hien, T.T., et al. (2013) Factors Associated with Dengue Shock Syndrome: A Systematic Review and Meta-Analysis. PLOS Neglected Tropical Diseases, 7, e2412. https://doi.org/10.1371/journal.pntd.0002412

[4] Gubler, D.J. (1998) Dengue and Dengue Hemorrhagic Fever. Clinical Microbiology Reviews, 11, 480-496. https://doi.org/10.1128/CMR.11.3.480

[5] World Health Organization (2009) Dengue Guidelines for Diagnosis, Treatment, Prevention and Control: New Edition. World Health Organization, Geneva. https://apps.who.int/iris/handle/10665/44188

[6] Villar-Centeno, L.A., Díaz-Quijano, F.A. and Martínez-Vega, R.A. (2008) Biochemical Alterations as Markers of Dengue Hemorrhagic Fever. The American Journal of Tropical Medicine and Hygiene, 78, 370-374. https://doi.org/10.4269/ajtmh.2008.78.370

[7] Chandrasena, L., De Silva, A., De Mel, C., Peiris, H., Abesuriya, V., De Mel, S., Seneviratne, S. and Bandara, S. (2019) Glutathione Enzymes and Liver Injury in Acute Dengue Viral Infection. Journal of Biosciences and Medicines, 7, 61-71. https://doi.org/10.4236/jbm.2019.710006

[8] Tissera, H., Rathore, A.P., Leong, W.Y., Pike, B.L., Warkentien, T.E., et al. (2017) Chymase Level Is a Predictive Biomarker of Dengue Hemorrhagic Fever in Pediatric and Adult Patients. The Journal of Infectious Diseases, 216, 1112-1121. https://doi.org/10.1093/infdis/jix447

[9] St John, A.L., Abraham, S.N. and Gubler, D.J. (2013) Barriers to Preclinical Investigations of Anti-Dengue Immunity and Dengue Pathogenesis. Nature Reviews Microbiology, 11, 420-426. https://doi.org/10.1038/nrmicro3030 
[10] Datta, L. and Menon, M.P. (2017) Plasmacytoid Lymphocytes: A Clue to Dengue Diagnosis. Blood, 129, 2202. https://doi.org/10.1182/blood-2017-01-762500

[11] Jampangern, W., Vongthoung, K., Jittmittraphap, A., Worapongpaiboon, S., Limkittikul, K., et al. (2007) Characterization of Atypical Lymphocytes and Immunophenotypes of Lymphocytes in Patients with Dengue Virus Infection. Asian Pacific Journal of Allergy and Immunology, 25, 27-36.

[12] Clarice, C.S.H., Abeysuriya, V., de Mel, S., Thilakawardana, B.U., de Mel, P., de Mel, C., et al. (2019) Atypical Lymphocyte Count Correlates with the Severity of Dengue Infection. PLoS ONE, 14, e0215061. https://doi.org/10.1371/journal.pone.0215061

[13] Abeysuriya, V., Choong, C.S.H., Thilakawardana, B.U., de Mel, P., Shalindi, M., de Mel, C., et al. (2020) The Atypical Lymphocyte Count: A Novel Predictive Factor for Severe Thrombocytopenia Related to Dengue. Transactions of the Royal Society of Tropical Medicine and Hygiene, 114, 424-432. https://doi.org/10.1093/trstmh/trz128

[14] Soundravally, R., Hoti, S.L., Patil, S.A., Cleetus, C.C., Zachariah, B., et al. (2014) Association between Proinflammatory Cytokines and Lipid Peroxidation in Patients with Severe Dengue Disease around Defervescence. International Journal of Infectious Diseases, 18, 68-72. https://doi.org/10.1016/j.ijid.2013.09.022

[15] Nasirudeen, A.M.A., Wong, H.H., Thien, P., Xu, S., Lam, K.P., et al. (2011) RIG-I, MDA5 and TLR3 Synergistically Play an Important Role in Restriction of Dengue Virus Infection. PLOS Neglected Tropical Diseases, 5, e926. https://doi.org/10.1371/journal.pntd.0000926

[16] Rajendiran, S., Lakshamanappa, H.S., Zachariah, B. and Nambiar, S. (2008) Desialylation of Plasma Proteins in Severe Dengue Infection: Possible Role of Oxidative Stress. The American Journal of Tropical Medicine and Hygiene, 79, 372-377. https://doi.org/10.4269/ajtmh.2008.79.372

[17] Chandrasena, L.G., Peiris, H., Kamani, J., Wanigasuriya, P., Jayaratne, S.D., et al. (2014) Antioxidants in Patients with Dengue Viral Infection. The Southeast Asian Journal of Tropical Medicine and Public Health, 45, 1015-1022.

[18] Fernando, S., Wijewickrama, A., Gomes, L., Punchihewa, C.T., Madusanka, S.D.P., et al. (2016) Patterns and Causes of Liver Involvement in Acute Dengue Infection. BMC Infectious Diseases, 16, 319. https://doi.org/10.1186/s12879-016-1656-2

[19] Franca, R.F., Zucoloto, S. and da Fonseca, B.A. (2010) A BALB/c Mouse Model Shows That Liver Involvement in Dengue Disease Is Immune-Mediated. Experimental and Molecular Pathology, 89, 321-326. https://doi.org/10.1016/j.yexmp.2010.07.007

[20] Zhang, H., Limphong, P., Pieper, J., Liu, Q., Rodesch, C.K., et al. (2012) Glutathion Dependent Reductive Stress Triggers Mitochondrial Oxidation and Cytotoxicity. The FASEB Journal, 26, 1442-1451. https://doi.org/10.1096/fj.11-199869

[21] Cacciatore, I., Cornacchia, C., Pinnen, F., Mollica, A. and Di Stefano, A. (2010) Pro Drug Approach for Increasing Cellular Glutathione Levels. Molecules, 15, 1242-1264. https://doi.org/10.3390/molecules 15031242

[22] Snyder, A.H., McPherson, M.E., Hunt, J.F., Johnson, M., Stamler, J.S. and Gaston, B. (2002) Acute Effects of Aerosolized S-Nitrosoglutathione in Cystic Fibrosis. American Journal of Respiratory and Critical Care Medicine, 165, 922-926. https://doi.org/10.1164/ajrccm.165.7.2105032

[23] Kumarasena, R.S., Mananjala, S.S., Sivaraman, K., De Silva, A.P., Dassanayake, A.S., et al. (2010) Intravenous N-Acetylcysteine in Dengue-Associated Acute Liver Failure. Hepatology International, 4, 533-534. 
https://doi.org/10.1007/s12072-010-9176-4

[24] Bandyopadhyay, D., Chattaraj, S., Hajra, A., Mukhopadhyay, S. and Ganesan, V. (2016) A Study on Spectrum of Hepatobiliary Dysfunctions and Pattern of Liver Involvement in Dengue Infection. Journal of Clinical and Diagnostic Research, 10, OC21-OC26. https://doi.org/10.7860/JCDR/2016/16946.7784

[25] Roy, A., Sarkar, D., Chakraborty, S., Chaudhuri, J. and Ghosh, P. (2013) Profile of Hepatic Involvement by Dengue Virus in Dengue Infected Children. North American Journal of Medical Sciences, 5, 480-485. https://doi.org/10.4103/1947-2714.117313

[26] Parkash, O., Almas, A., Jafri, S.M., Hamid, S., Akhtar, J., et al. (2010) Severity of Acute Hepatitis and Its Outcome in Patients with Dengue Fever in a Tertiary Care Hospital Karachi, Pakistan (South Asia). BMC Gastroenterology, 10, 43. https://doi.org/10.1186/1471-230X-10-43

[27] Souza, L.J., Alves, J.G., Nogueira, R.M.R., Gicovate Neto, C., Bastos, D.A., et al. (2004) Aminotransferase Changes and Acute Hepatitis in Patients with Dengue Fever: Analysis of 1,585 Cases. Brazilian Journal of Infectious Diseases, 8, 156-163. https://doi.org/10.1590/S1413-86702004000200006

[28] Trung, D.T., Thao, L.T.T., Hien, T.T., Hung, N.T., Vinh, N.N., et al. (2010) Liver Involvement Associated with Dengue Infection in Adults in Vietnam. The American Journal of Tropical Medicine and Hygiene, 83, 774-780. https://doi.org/10.4269/ajtmh.2010.10-0090

[29] Kalayanarooj, S., Vaughn, D.W., Nimmannitya, S., Green, S., Suntayakorn, S., et al. (1997) Early Clinical and Laboratory Indicators of Acute Dengue Illness. The Journal of Infectious Diseases, 176, 313-321. https://doi.org/10.1086/514047 